\title{
Beyond a single pathway: combination therapy in pulmonary arterial hypertension
}

\author{
Olivier Sitbon ${ }^{1,2,3}$ and Sean Gaine ${ }^{4}$
}

\begin{abstract}
Affiliations: ${ }^{1}$ Univ. Paris-Sud, Université Paris-Saclay, Le Kremlin-Bicêtre, France. ${ }^{2}$ AP-HP, Service de Pneumologie, Centre de Référence de l'Hypertension Pulmonaire Sévère, DHU Thorax Innovation, Hôpital Bicêtre, Le Kremlin-Bicêtre, France. ${ }^{3}$ INSERM UMR_S 999, Le Plessis Robinson, France. ${ }^{4}$ National Pulmonary Hypertension Unit, Mater Misericordiae University Hospital, Dublin, Ireland.
\end{abstract}

Correspondence: Olivier Sitbon, Service de Pneumologie et Soins Intensifs, CHU de Bicêtre, 78 rue du Général Leclerc, F-94275, Le Kremlin-Bicêtre, France. E-mail: olivier.sitbonabct.aphp.fr

ABSTRACT There is a strong rationale for combining therapies to simultaneously target three of the key pathways implicated in the pathogenesis of pulmonary arterial hypertension (PAH). Evidence to support this strategy is growing, and a number of studies have demonstrated that combination therapy, administered as either a sequential or an initial regimen, can improve long-term outcomes in PAH. Dual combination therapy with a phosphodiesterase-5 inhibitor and an endothelin receptor antagonist is the most widely utilised combination regimen. However, some patients fail to achieve their treatment goals on dual therapy and may benefit from the addition of a third drug. The use of triple therapy in clinical practice was previously reserved for patients with severe disease due to the need for parenteral administration of prostanoids. Although triple therapy with parenteral prostanoids plays a key role in the management of severe $\mathrm{PAH}$, the approval of oral therapies that target the prostacyclin pathway means that all three pathways can now be targeted with oral drugs at an earlier disease stage. Furthermore, there is evidence demonstrating that this approach can delay disease progression. Based on the evidence available, it is becoming increasingly clear that all PAH patients should be offered the benefits of combination therapy.

0 $@$ ERSpublications

Targeting multiple pathways with combination therapy can benefit PAH patients by delaying disease progression http://ow.ly/tDaS304X25p

\section{Introduction}

There is a strong rationale for the use of combination therapy in the treatment of many chronic diseases. Combination therapy allows distinct pathogenic pathways to be targeted simultaneously, leading to additive or synergistic beneficial effects. Multiple therapies can either be initiated at the same time, i.e. as initial combination therapy, or started one after the other, i.e. as sequential combination therapy. There is now evidence supporting the benefit of combining drugs in many disorders, including HIV [1, 2], heart failure [3, 4], systemic hypertension [5] and cancer [6, 7]. Studies in these disease areas have shown that the more therapies that are combined, the greater the clinical benefit. Indeed, there is a direct correlation between the number of agents used and the cure rate in childhood acute lymphoblastic leukaemia [7]. Furthermore, using multiple combination therapy to intensively manage systemic hypertension, to the point where adverse event rates increased, led to a reduced risk of morbidity and mortality compared with standard management using fewer therapies [5].

Editorial comment in Eur Respir Rev 2016; 25: 361-363.

Received: Aug 182016 | Accepted after revision: Sept 302016

Conflict of interest: Disclosures can be found alongside this article at err.ersjournals.com

Provenance: The European Respiratory Review received sponsorship from Actelion Pharmaceuticals Ltd, Allschwil, Switzerland, for the publication of these peer-reviewed articles.

Copyright CERS 2016. ERR articles are open access and distributed under the terms of the Creative Commons Attribution Non-Commercial Licence 4.0. 
In pulmonary arterial hypertension (PAH), therapies targeting three separate pathogenic pathways are available (the endothelin, nitric oxide and prostacyclin $\left(\mathrm{PGI}_{2}\right)$ pathways). When used as monotherapy, each of the approved $\mathrm{PAH}$-specific therapies demonstrated efficacy in clinical trials leading to their regulatory approval. However, despite the growing number of targeted therapies that are available, PAH patients continue to deteriorate and the disease ultimately remains fatal. Combining the different classes of drugs to target all three pathways has long been considered a promising treatment strategy for this devastating disease, and with the development of larger, longer term and more sophisticated PAH trials, the clear benefits of dual and triple combination therapy are finally beginning to emerge [8-10]. This is reflected by recommendations in the current European Society of Cardiology (ESC)/European Respiratory Society (ERS) guidelines, in which combination therapy now plays a central part in the treatment algorithm [11, 12]. In this article, we review the recent studies that have investigated combination therapy in PAH, focusing on the key roles of both dual and triple combination therapy in the management of this disease.

\section{Dual combination therapy in PAH}

The majority of trials that have examined combination therapy in $\mathrm{PAH}$ have investigated whether targeting two pathogenic pathways at once, either with initial or sequential therapy, is superior to monotherapy [11]. Although dual combination therapy is now widespread in clinical practice [13], the results of early short-term trials investigating this treatment approach were inconsistent [14-25]. A comprehensive overview of these studies is provided in table 1 , including some that have shown a positive treatment response with respect to change in 6-min walking distance (6MWD) (e.g. PACES-1 [18] and TRIUMPH [17]) and some that have not (e.g. COMBI [14] and STEP [15]). One possible explanation for this inconsistency is the use of exercise capacity as the primary end-point; a ceiling effect for 6MWD may exist in patients who are already on background therapy, such that the addition of a second therapy leads to only modest or no improvement in exercise capacity [26]. Furthermore, it has become increasingly clear that there is no association between change in 6MWD and improvements in long-term outcomes for patients with $\mathrm{PAH}[27,28]$. Due to the limitations of using change in $6 \mathrm{MWD}$ as a primary end-point, dual combination therapy was subsequently investigated in four long-term outcome trials [8-10, 25]. Three of these studies demonstrated that this treatment strategy delayed disease progression compared with monotherapy, regardless of whether an initial or sequential strategy was employed (table 1) [8-10]. The evidence supporting dual combination therapy from these randomised controlled trials (RCTs) is summarised below, along with real-world data that illustrate the benefits of this approach in clinical practice.

\section{Sequential dual combination therapy in PAH}

The first RCT to show the long-term benefits of sequential dual combination therapy was SERAPHIN, a double-blind, placebo-controlled, phase 3 study in $742 \mathrm{PAH}$ patients [8]. In the overall study population, macitentan $10 \mathrm{mg}$ significantly reduced the risk of a morbidity/mortality event (composite primary end-point) by $45 \%(\mathrm{p}<0.001)$ versus placebo. The treatment effect was driven by differences in the rate of worsening of PAH. Of note, almost two-thirds of patients enrolled in SERAPHIN were taking background PAH-specific therapy at baseline, with $96 \%$ of these on phosphodiesterase type-5 inhibitors (PDE-5i) [8]. For this subgroup, macitentan $10 \mathrm{mg}$ significantly reduced the risk of a morbidity/mortality event (composite primary end-point) by $38 \%(\mathrm{p}=0.009)$ versus placebo (figure 1) [8], highlighting that sequential combination therapy can improve long-term outcomes in PAH. Furthermore, macitentan $10 \mathrm{mg}$ significantly improved 6MWD by $25.9 \mathrm{~m}$ from baseline to month 6 versus placebo $(\mathrm{p}=0.007)$ in patients on background therapy [8]. A haemodynamic substudy enrolling 187 patients from 38 centres indicated that macitentan $10 \mathrm{mg}$ also significantly improved pulmonary vascular resistance (PVR) (mean (95\% CI) treatment effect with $10 \mathrm{mg}$ dose versus placebo: $-36.9(-48.5--22.7) \%$; $\mathrm{p}=0.0001)$ and cardiac index (mean treatment effect with $10 \mathrm{mg}$ dose versus placebo: $\left.0.61(0.24-0.98) \mathrm{L} \cdot \mathrm{min}^{-1} \cdot \mathrm{m}^{-2} ; \mathrm{p}=0.0045\right)$ from baseline to month 6 in patients on background therapy [29]. Post hoc analyses were performed to investigate the effect of macitentan on hospitalisation. These analyses demonstrated that macitentan $10 \mathrm{mg}$ reduced the risk of PAH-related hospitalisation in patients on background therapy by $37.4(0.406-0.964) \%$ [30]. To investigate the effect of macitentan in newly diagnosed patients with $\mathrm{PAH}$, a post hoc analysis was performed in incident patients, including those on background therapy [31]. In these patients, macitentan $10 \mathrm{mg}$ significantly reduced the risk of morbidity/mortality by $57 \%(\mathrm{p}=0.001)$ [31]. The published data from SERAPHIN report a similar percentage of patients discontinuing treatment due to adverse events in the macitentan and placebo groups [8], demonstrating the safety of macitentan administration both as monotherapy and as part of a combination therapy regimen. Subsequently, the safety and tolerability of macitentan in a real-world setting has been evaluated in the OPsumit USers registry (OPUS). Similar to SERAPHIN, approximately two-thirds of patients enrolled in the OPUS registry were receiving background PAH therapy. The safety profile of macitentan as a monotherapy and in combination with other PAH-specific therapies in the OPUS registry was consistent with that observed in the clinical study setting, and revealed no unexpected safety findings [32, 33]. 
TABLE 1 Combination therapy data from randomised controlled trials

\begin{tabular}{|c|c|c|c|c|c|c|c|}
\hline Study name & Patients & $\begin{array}{l}\text { PAH treatment } \\
\text { at baseline }\end{array}$ & $\begin{array}{l}\text { Investigational } \\
\text { therapy }\end{array}$ & Comparator & Primary end-point & Study duration & $\begin{array}{l}\text { Primary end-point met } \\
\text { in overall population }\end{array}$ \\
\hline \multicolumn{8}{|l|}{ Sequential combination } \\
\hline PACES-1 [18] & 267 & $\begin{array}{l}\text { Epoprostenol i.v. } \\
267(100)\end{array}$ & Sildenafil & Placebo & 6MWD & 16 weeks & Yes \\
\hline Zhuang et al. 2014 [21] & 124 & Ambrisentan 124 (100) & Tadalafil & Placebo & 6MWD & 16 weeks & Yes \\
\hline PHIRST [19] & 405 & $\begin{array}{c}\text { None } 189 \text { (47) } \\
\text { Bosentan } 216 \text { (53) }\end{array}$ & Tadalafil & Placebo & $6 \mathrm{MWD}$ & 16 weeks & Yes $^{\#}$ \\
\hline PATENT-1 [20] & 443 & $\begin{array}{c}\text { None } 221(50) \\
\text { ERA } 194(44) \\
\text { Prostanoids } \\
\text { Pl } 28(6)\end{array}$ & Riociguat & Placebo & $6 \mathrm{MWD}$ & 12 weeks & Yes $^{\#}$ \\
\hline COMBI [14] & 40 & Bosentan 40 (100) & Inhaled iloprost & $\mathrm{None}^{+}$ & 6MWD & 12 weeks & No \\
\hline STEP [15] & 67 & Bosentan $67(100)$ & Inhaled iloprost & Placebo & 6MWD & 12 weeks & No \\
\hline TRIUMPH [17] & 235 & $\begin{array}{l}\text { Bosentan } 165(70) \\
\text { Sildenafil } 70(30)\end{array}$ & Inhaled treprostinil & Placebo & $6 \mathrm{MWD}$ & 12 weeks & Yes \\
\hline FREEDOM-C [23] & 350 & $\begin{array}{c}\text { ERA, } 106(30) \\
\text { PDE-5i } 88(25) \\
\text { ERA and PDE-5i } \\
156(45)\end{array}$ & Oral treprostinil & Placebo & $6 \mathrm{MWD}$ & 16 weeks & No \\
\hline FREEDOM-C2 [24] & 310 & $\begin{array}{c}\text { ERA } 53(17) \\
\text { PDE-5i } 132(43) \\
\text { ERA and PDE-5i } \\
125(40)\end{array}$ & Oral treprostinil & Placebo & $6 M W D$ & 16 weeks & No \\
\hline EARLY [16] & 185 & $\begin{array}{c}\text { None } 156 \text { (84) } \\
\text { Sildenafil } 29(16)\end{array}$ & Bosentan & Placebo & PVR and $6 \mathrm{MWD}$ & 26 weeks & $\begin{array}{l}\text { PVR: yes } \\
6 \text { MWD: no }\end{array}$ \\
\hline COMPASS-2 [25] & 334 & Sildenafil 334 (100) & Bosentan & Placebo & $\begin{array}{l}\text { Composite of morbidity/ } \\
\text { mortality }\end{array}$ & $\begin{array}{c}\text { Mean } \\
114.4 \text { weeks }^{\S}\end{array}$ & No \\
\hline SERAPHIN [8] & 742 & $\begin{array}{c}\text { None } 268(36) \\
\text { PDE-5i } 454(61) \\
\text { Oral/inhaled prostanoid } \\
40(5)\end{array}$ & Macitentan & Placebo & $\begin{array}{c}\text { Composite of morbidity/ } \\
\text { mortality }\end{array}$ & $\begin{array}{l}\text { Median } \\
115 \text { weeks }\end{array}$ & Yes $^{\#}$ \\
\hline GRIPHON [10] & 1156 & $\begin{array}{c}\text { None } 236(20) \\
\text { ERA } 170(15) \\
\text { PDE-5i } 374(32) \\
\text { ERA and PDE-5i } \\
376(33)\end{array}$ & Selexipag & Placebo & $\begin{array}{c}\text { Composite of morbidity/ } \\
\text { mortality }\end{array}$ & $\begin{array}{l}\text { Median } \\
67 \text { weeks }\end{array}$ & Yes $^{\#}$ \\
\hline \multicolumn{8}{|c|}{$\begin{array}{l}\text { Initial combination in } \\
\text { treatment-naïve patients }\end{array}$} \\
\hline BREATHE-2 [22] & 33 & None & $\begin{array}{l}\text { Epoprostenol and } \\
\text { bosentan }\end{array}$ & $\begin{array}{l}\text { Epoprostenol and } \\
\text { placebo }\end{array}$ & $\begin{array}{l}\text { Total pulmonary } \\
\text { resistance }\end{array}$ & 16 weeks & No \\
\hline AMBITION [9] & $500^{f}$ & None & $\begin{array}{c}\text { Ambrisentan and } \\
\text { tadalafil }\end{array}$ & $\begin{array}{c}\text { Ambrisentan or } \\
\text { tadalafil }\end{array}$ & $\begin{array}{l}\text { Composite of clinical } \\
\text { failure }\end{array}$ & $\begin{array}{c}\text { Mean } \\
73.9 \text { weeks }\end{array}$ & Yes \\
\hline
\end{tabular}

Data are presented as $\mathrm{n}$ or $\mathrm{n}(\%)$, unless otherwise stated. Patients were randomised as follows: BREATHE-2 (2:1 bosentan:placebo); AMBITION (2:1:1 ambrisentan/tadalafil combination: ambrisentan monotherapy:tadalafil monotherapy); SERAPHIN (1:1:1 macitentan $10 \mathrm{mg}: \mathrm{macitentan} 3 \mathrm{mg}:$ placebo); PHIRST (1:1:1:1:1/placebo:tadalafil 2.5 mg:10 mg:20 mg:40 mg); PATENT-1 (2:4:1 placebo:riociguat $2.5 \mathrm{mg}$ max:1.5 mg max). For all other studies the patients were randomised 1:1 between treatment arms. PAH: pulmonary arterial hypertension; 6MWD: 6-min walking distance; ERA: endothelin receptor antagonist; PDE-5i: phosphodiesterase type-5 inhibitor; PVR: pulmonary vascular resistance. \#: the result in the subgroup of patients who were on background therapy was consistent with that for the overall population in the PATENT-1, EARLY, SERAPHIN and GRIPHON trials. In PHIRST, the primary end-point was not met in the subgroup of patients who were receiving background therapy; ${ }^{1}$ : patients receiving i.v. prostanoids were excluded: ${ }^{+}$: patients in this study either received bosentan only (no placebo inhalations) or bosentan with inhaled iloprost; ${ }^{\S}$ : duration of active treatment (bosentan arm); ${ }^{f}: 610$ participants were randomised and 500 included in the primary analysis set. 
FIGURE 1 Macitentan as part of combination therapy significantly reduced the risk of morbidity/ mortality events (composite primary end-point) versus placebo in incident and prevalent pulmonary arterial hypertension (PAH) patients. Kaplan-Meier curves for PAH patients receiving background PAH-specific therapy at baseline. HR: hazard ratio. \#: log rank. Reproduced and modified from [8] with permission from the publisher.

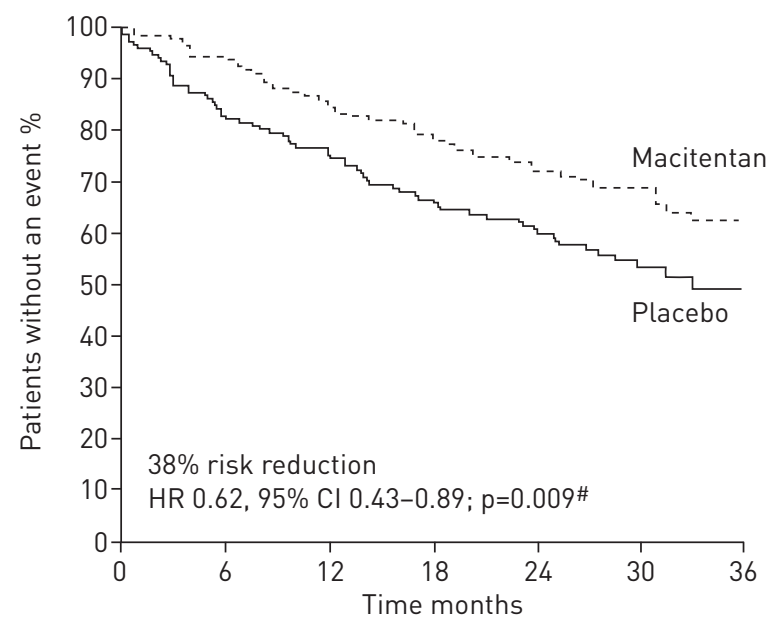

Patients at risk $\mathrm{n}$

Placebo $\quad 154$

Macitentan 154

$54 \quad 122$

90

107
80

97

$40 \quad 10$

The effect of combining an endothelin receptor antagonist (ERA) and a PDE-5i sequentially was also investigated in COMPASS-2, a double-blind, placebo-controlled, phase 4 RCT in $334 \mathrm{PAH}$ patients [25]. In this study, the addition of bosentan in patients who were already receiving a stable dose of sildenafil did not reduce the risk of a morbidity/mortality event (composite primary end-point) compared with placebo $(p=0.2508)$ [25]. However, bosentan did significantly improve 6MWD by $21.8 \mathrm{~m}$ at week 16 versus placebo ( $\mathrm{p}=0.0106)$ and prevented the increase in $N$-terminal pro-brain natriuretic peptide (NT-proBNP) that was observed in patients in the placebo arm $(\mathrm{p}=0.0003)$ [25]. When added to sildenafil, the safety profile of bosentan was consistent with its known safety profile when used as a monotherapy [25]. It is not clear why this combination of drugs did not significantly improve morbidity/mortality in COMPASS-2, when other RCTs have shown that this combination of drug classes is effective $[8,9]$. Possible reasons include that COMPASS- 2 was designed to detect a large treatment effect of $>40 \%$; the number of morbidity/ mortality events that occurred in the study was potentially too few to detect a smaller, but possibly meaningful, effect [25]. Furthermore, there was a sizeable amount of missing data for the primary end-point as a result of patients prematurely discontinuing the study prior to experiencing a primary end-point event [25]. Given the limitations, the authors of the COMPASS-2 publication concluded that the results of the study must be interpreted with caution [25].

Sequential combination therapy with an ERA and PDE-5i has also been assessed in the real-world setting. In a single-centre retrospective analysis of $192 \mathrm{PAH}$ patients who displayed an inadequate response to monotherapy with bosentan or sildenafil, the effect of adding sildenafil or bosentan was investigated [34]. This study reported significant improvements from baseline in haemodynamic parameters, World Health Organization (WHO) functional class and 6MWD after 3-4 months of combination therapy [34]. Overall 1 -, 3- and 5-year survival estimates of $91 \%, 69 \%$ and 59\%, respectively, were observed in patients receiving sequential combination therapy [34]. Furthermore, the combination of bosentan and sildenafil was well tolerated [34]. Although these data are subject to limitations given their uncontrolled nature, this evidence indicates that bosentan and sildenafil can be beneficial when used as sequential combination therapy.

The studies conducted to date and described in this review have focused on dual combination therapy with an ERA and PDE-5i. Historically, the endothelin and nitric oxide pathways were easier to target in PAH, due to the availability of oral therapies that act upon these pathways. Targeting the $\mathrm{PGI}_{2}$ pathway was arguably more complicated, given that the prostanoid therapies available had complex routes of administration [35] and were subsequently often reserved for patients with severe disease $[11,12]$. With the approval of oral therapies that target the $\mathrm{PGI}_{2}$ pathway $[11,36]$, combination therapy that incorporates activation of $\mathrm{PGI}_{2}$ signalling has now become accessible to more patients, including those with less severe disease. Recently, the GRIPHON study has provided long-term data on sequential dual combination therapy with the oral IP prostacyclin receptor agonist selexipag, in patients who were predominantly in WHO functional class II or III [10]. In this double-blind, placebo-controlled, phase 3 RCT, selexipag or placebo were administered to 1156 patients who were treatment-naïve or on background therapy with either an ERA, a PDE-5i or both an ERA and PDE-5i [10]. At baseline, almost half (47\%) of the patients were on background monotherapy, allowing the effect of selexipag as part of dual combination therapy to be investigated in this subgroup [10]; the effects of selexipag as part of triple combination therapy in patients on dual background therapy are 
discussed later in this review. In the overall study population, selexipag reduced the risk of morbidity/ mortality (composite primary end-point) by $40 \%$ versus placebo $(\mathrm{p}<0.001)$ [10]. The treatment effect was driven by differences in disease progression and hospitalisation for worsening of PAH. Prespecified subgroup analysis by PAH therapy at baseline showed that the treatment effect on morbidity/mortality for patients on background monotherapy was consistent with the overall treatment effect (PDE-5i background therapy: risk reduction 42\%, hazard ratio (HR) 0.58 (99\% CI 0.37-0.91); ERA background therapy: risk reduction 34\%, HR 0.66 (99\% CI 0.32-1.35)) (figure 2) [10,37]. These data indicate that selexipag provides added benefits when sequentially combined with either an ERA or PDE-5i [37]. The safety and tolerability of selexipag in each of the background therapy subgroups has also been evaluated and no new adverse events were observed with selexipag when combined with an ERA and/or PDE-5i [38].

\section{Initial dual combination therapy in PAH}

The first randomised, placebo-controlled study to investigate initial dual combination therapy in PAH was BREATHE-2 [22]. In this study, intravenous epoprostenol was combined with bosentan or placebo in 33 patients with severe PAH in WHO functional class III or IV [22]. The primary end-point was the change in total pulmonary resistance (TPR) from baseline to week 16. TPR decreased to a greater extent in the

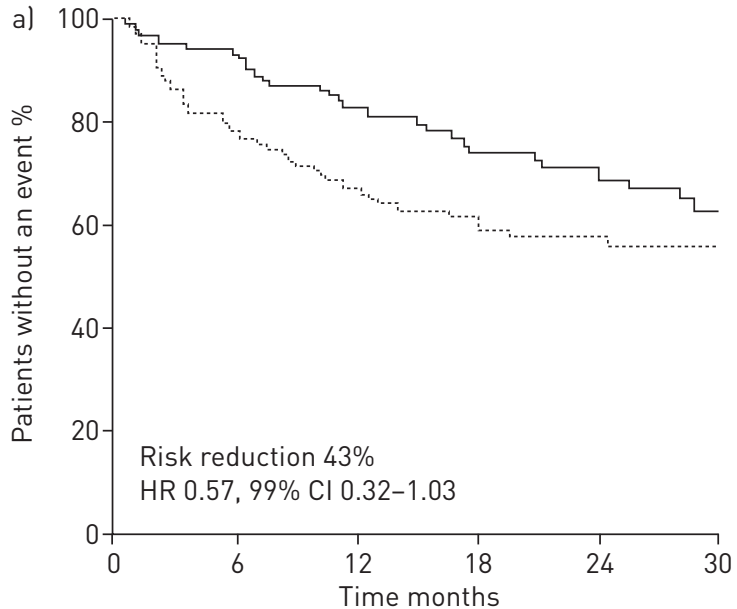

Patients at risk $n$

$\begin{array}{lllllll}\text { Placebo } & 124 & 84 & 67 & 45 & 33 & 23 \\ \text { Selexipag } & 112 & 97 & 81 & 49 & 40 & 23\end{array}$

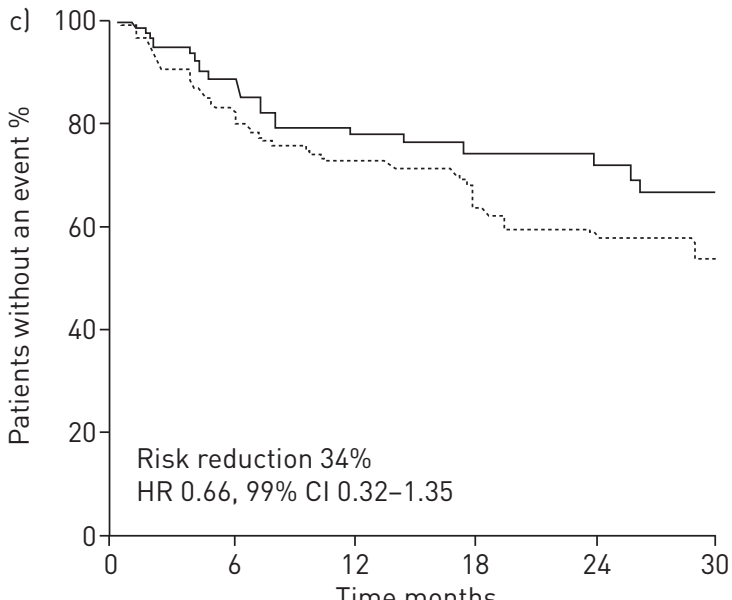

Patients at risk $\mathrm{n}$

$\begin{array}{lllllll}\text { Placebo } & 76 & 56 & 47 & 32 & 23 & 11 \\ \text { Selexipag } & 94 & 67 & 50 & 36 & 29 & 17\end{array}$

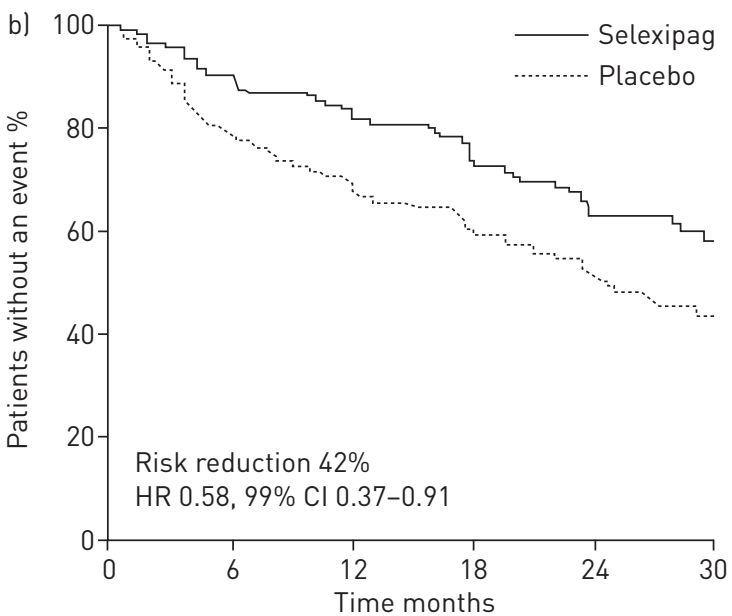

Patients at risk $n$

$\begin{array}{lllllll}\text { Placebo } & 185 & 135 & 114 & 73 & 49 & 27 \\ \text { Selexipag } & 189 & 151 & 125 & 91 & 59 & 30\end{array}$

FIGURE 2 Selexipag significantly reduced the risk of morbidity/mortality (composite primary end-point) versus placebo in incident and prevalent pulmonary arterial hypertension (PAH) patients. Kaplan-Meier curves for al patients not on background PAH therapy at baseline; b) patients on phosphodiesterase type-5 inhibitor (PDE-5i) monotherapy at baseline; c) patients on endothelin receptor antagonist (ERA) monotherapy at baseline; and d) patients on dual combination therapy (ERA + PDE-5i). HR: hazard ratio. Reproduced with permission [37]. 
bosentan group (mean \pm SEM $-36.3 \pm 4.3 \%$ ) compared with the placebo group $(-22.6 \pm 6.2 \%$ ); however, the difference was not statistically significant $(p=0.08)$ [22]. As only 33 patients were enrolled in BREATHE-2, the lack of a significant treatment effect may have been due to the small sample size [22]. Interestingly, the majority of adverse events associated with epoprostenol occurred less frequently in the combination therapy group compared with the epoprostenol monotherapy group [22].

The trend towards an improvement in haemodynamics observed with initial combination therapy in BREATHE-2 provided the rationale to further investigate this approach in PAH. Important data were subsequently generated from a retrospective observational study of 23 patients with severe PAH who were enrolled in the French registry and treated with initial epoprostenol and bosentan combination therapy [39]. Significant improvements from baseline were observed in 6MWD, WHO functional class and haemodynamics (including cardiac index, PVR and mixed venous oxygen saturation) after $\sim 4$ months of combination therapy; these improvements were also maintained during long-term treatment (mean $\pm \mathrm{SD}$ follow-up time of $30 \pm 19$ months) [39]. Compared with a historical control group on epoprostenol monotherapy, patients treated with initial dual combination therapy had a significantly greater improvement in PVR from baseline to month 4. There was also a trend towards improved overall survival with combination therapy; however, this was not statistically significant [39]. In terms of safety, initial combination therapy was not associated with increases in epoprostenol or bosentan-related side-effects [39].

More recently, the AMBITION study has provided data supporting the use of initial combination therapy in PAH [9]. AMBITION was a double-blind RCT which was designed to evaluate the treatment strategy of initial combination therapy with ambrisentan and tadalafil versus monotherapy with either agent in 500 newly diagnosed treatment-naïve PAH patients [9]. The two drugs were initiated at half of their maximum approved doses and then up-titrated to their maximum approved doses (tadalafil $40 \mathrm{mg}$ [40] and ambrisentan $10 \mathrm{mg}$ [41]) over a period of 8 weeks. There was a 50\% risk reduction in clinical failure events (composite primary end-point) for patients on combination therapy compared with the pooled monotherapy group $(\mathrm{p}<0.001)$ (figure 3) [9]. The treatment effect was driven by a difference in hospitalisation for worsening of PAH. At week 24, significant differences in favour of combination therapy were also observed in the percentage of patients with a satisfactory clinical response $(p=0.03)$ and in the change from baseline in 6MWD $(+49 \mathrm{~m}$ in the combination therapy arm versus $+24 \mathrm{~m}$ in the pooled monotherapy arm $(\mathrm{p}<0.001))$ and NT-proBNP $(-67.2 \%$ in the combination therapy arm versus $-50.4 \%$ in the pooled monotherapy arm $(\mathrm{p}<0.001))$ [9]. No significant differences were found between the study groups in WHO functional class [9]. Peripheral oedema (which occurred in almost half of the patients treated with the combination regimen), headache, nasal congestion and anaemia were more common in the combination therapy group compared with either monotherapy group. The rates of study drug discontinuation and serious adverse events were similar between groups [9]. Haemodynamic data from a substudy of 30 patients in AMBITION who were enrolled at a single centre showed that initial combination therapy also led to statistically significant improvements in cardiac index and PVR at month 6 compared with the pooled monotherapy group [42]. The effect of initial combination therapy with ambrisentan and tadalafil has also been investigated in an open-label study in 24 systemic sclerosis patients with moderate to severe PAH [43], which assessed haemodynamics and parameters of right ventricular size and function.

FIGURE 3 Initial combination therapy with ambrisentan and tadalafil significantly reduced the risk of clinical failure (composite primary end-point) versus pooled monotherapy in incident pulmonary arterial hypertension patients. Kaplan-Meier curves for treatment-naïve pulmonary arterial hypertension patients. HR: hazard ratio. Reproduced from [9] with permission from the publisher.

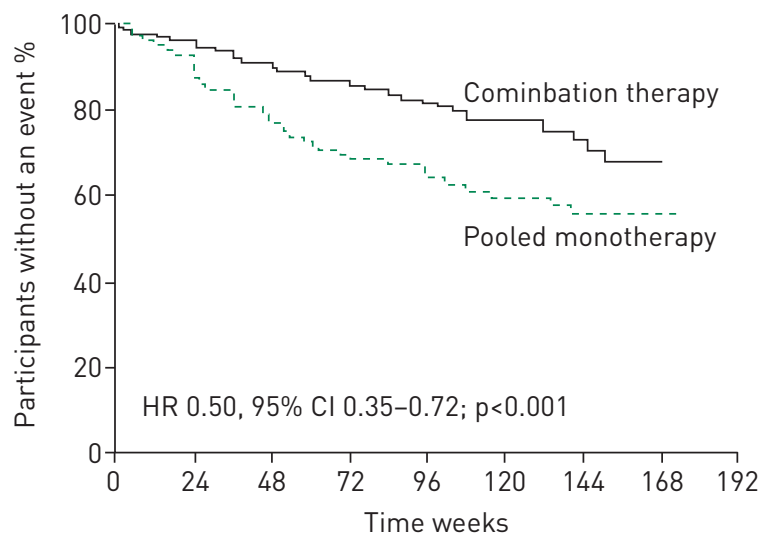

Patients at risk $\mathrm{n}$ Combination 253 therapy

Pooled 247

229

20

186

145

106

$71 \quad 36$

monotherapy 
Initial combination therapy resulted in statistically significant reductions from baseline to week 36 in the co-primary end-points of right ventricular mass $(14 \%$ reduction; $\mathrm{p}<0.05)$ and PVR (55\% reduction; $\mathrm{p}<0.01)[43]$.

The benefits of initial dual therapy using different ERAs and PDE-5is have also been shown using real-world data. A retrospective analysis was performed on data from 97 newly diagnosed PAH patients enrolled in the French registry [44]. Patients on initial combination therapy with an ERA (bosentan or ambrisentan) and a PDE-5i (sildenafil or tadalafil) were studied for a median follow-up period of 30 months [44]. Combination therapy (pooled analysis) led to a statistically significant improvement from baseline in WHO functional class, 6MWD, clinical signs of right heart failure, dyspnoea, brain natriuretic peptide (BNP) and haemodynamics (including cardiac index and PVR) after a median duration of 4.1 months of therapy; these improvements were sustained during long-term follow-up (median duration 24.6 months) [44]. Short-term reductions in PVR compared with baseline exceeded $40 \%$ regardless of the combination regimen used (i.e. when a PDE-5i was combined with either bosentan or ambrisentan, and an ERA was combined with either sildenafil or tadalafil) [44]. Analysis of the subgroup of patients with idiopathic $\mathrm{PAH}$, heritable $\mathrm{PAH}$ and anorexigen-induced $\mathrm{PAH}$ showed improved survival rates for patients on initial dual combination therapy $(96 \%, 94 \%$ and $84 \%$ at 1,2 and 3 years, respectively) compared with predicted survival rates calculated using the French equation [44]. In this study, dual combination therapy was generally well tolerated, with patients experiencing adverse events consistent with the known adverse event profiles for these drugs [44].

\section{Triple combination therapy in PAH}

Combining two classes of drugs is an important treatment option for PAH; however, for many patients dual combination therapy may not be sufficient to achieve the treatment goal of a low risk status recommended in the current ESC/ERS guidelines [11, 12]. Not only are many patients unable to achieve a low risk status while on dual combination therapy, but a significant number may experience a clinically significant event while on an ERA and PDE-5i [8,9]. Given that there are therapies available to target three distinct pathophysiological pathways in $\mathrm{PAH}$, there is a clear scientific rationale for investigating the benefits of triple combination therapy for these patients. Studies that provide data on this strategy are summarised in this section.

\section{Sequential triple combination therapy in PAH}

Currently, data from RCTs designed specifically to assess the benefits of adding a third therapy to a dual combination therapy regimen in PAH are lacking. However, three RCTs have included a large population of patients on dual background therapy, thereby providing an opportunity to investigate the effect of triple versus dual combination therapy $[10,23,24]$. The first two, FREEDOM-C [23] $(\mathrm{n}=350)$ and FREEDOM-C2 [24] $(\mathrm{n}=310)$, investigated the efficacy and safety of oral treprostinil versus placebo in patients receiving background therapy with an ERA and/or a PDE-5i. In both studies, a large proportion of patients were on dual combination therapy at baseline $(45 \%$ in FREEDOM-C and $40 \%$ in FREEDOM-C2) $[23,24]$. In these short-term trials, oral treprostinil failed to demonstrate any significant benefit on the primary end-point of change in $6 \mathrm{MWD}$, either as dual or triple combination therapy [23, 24]. Furthermore, a recent single-centre study of patients in the FREEDOM studies reported no significant improvement in WHO functional class, $6 \mathrm{MWD}$ or haemodynamics after $\sim 1$ year of therapy with oral treprostinil, potentially due to an inability to achieve a clinically effective dose [45].

In the GRIPHON study, described earlier, 376 patients (32.5\% of the total population) were on dual ERA and PDE-5i therapy at baseline [10]. Administration of selexipag or placebo to these patients allowed triple versus dual combination therapy to be studied [10]. A prespecified analysis evaluating the composite primary end-point of morbidity/mortality demonstrated that selexipag reduced the risk of a primary end-point event in patients receiving dual combination therapy at baseline by $37 \%$ (HR 0.63, 99\% CI 0.391.01) (figure 2) [37]. These data support the addition of selexipag patients treated with an ERA and a PDE-5i to improve long-term outcomes in WHO functional class II/III patients with PAH.

\section{Initial triple combination therapy in PAH}

A retrospective study of 19 newly diagnosed patients with severe PAH (WHO functional class III and IV) from the French registry demonstrated that initial triple combination therapy can offer long-term benefits [46]. In this study, significant improvements in 6MWD and haemodynamics were observed after 4 months of triple combination therapy with i.v. epoprostenol, bosentan and sildenafil in 18 patients $(\mathrm{p}=0.01)$. Furthermore, 17 patients improved to WHO functional class I or II [46]. These effects were maintained during long-term treatment (median follow-up of 32 months) [46]. Survival estimates were $100 \%$ at 3 years, which was superior to the expected 3-year survival (49\%) calculated from the French registry risk equation [46]. Most adverse events experienced in this study were typical of epoprostenol therapy [46]. 
This study highlights the benefits of treating high-risk patients with combination therapy including i.v. epoprostenol. Based on data supporting triple and dual combination therapy regimens including i.v. epoprostenol $[22,39,46]$, and as i.v. epoprostenol monotherapy has been shown to reduce mortality in patients with severe PAH [47], the ESC/ERS guidelines state that high-risk patients should receive initial combination therapy that includes i.v. epoprostenol $[11,12]$.

The previously described study provided strong preliminary evidence for the benefit of an initial triple combination regimen in incident patients with severe PAH. In order to provide more robust evidence to support the benefits of this treatment strategy in PAH, an initial triple combination therapy RCT has now been initiated. The objective of this phase $3 \mathrm{~b}$ trial, termed TRITON, is to compare the efficacy and safety of an initial dual oral treatment regimen (macitentan, tadalafil and placebo) versus an initial triple oral combination regimen (macitentan, tadalafil and selexipag) [48].

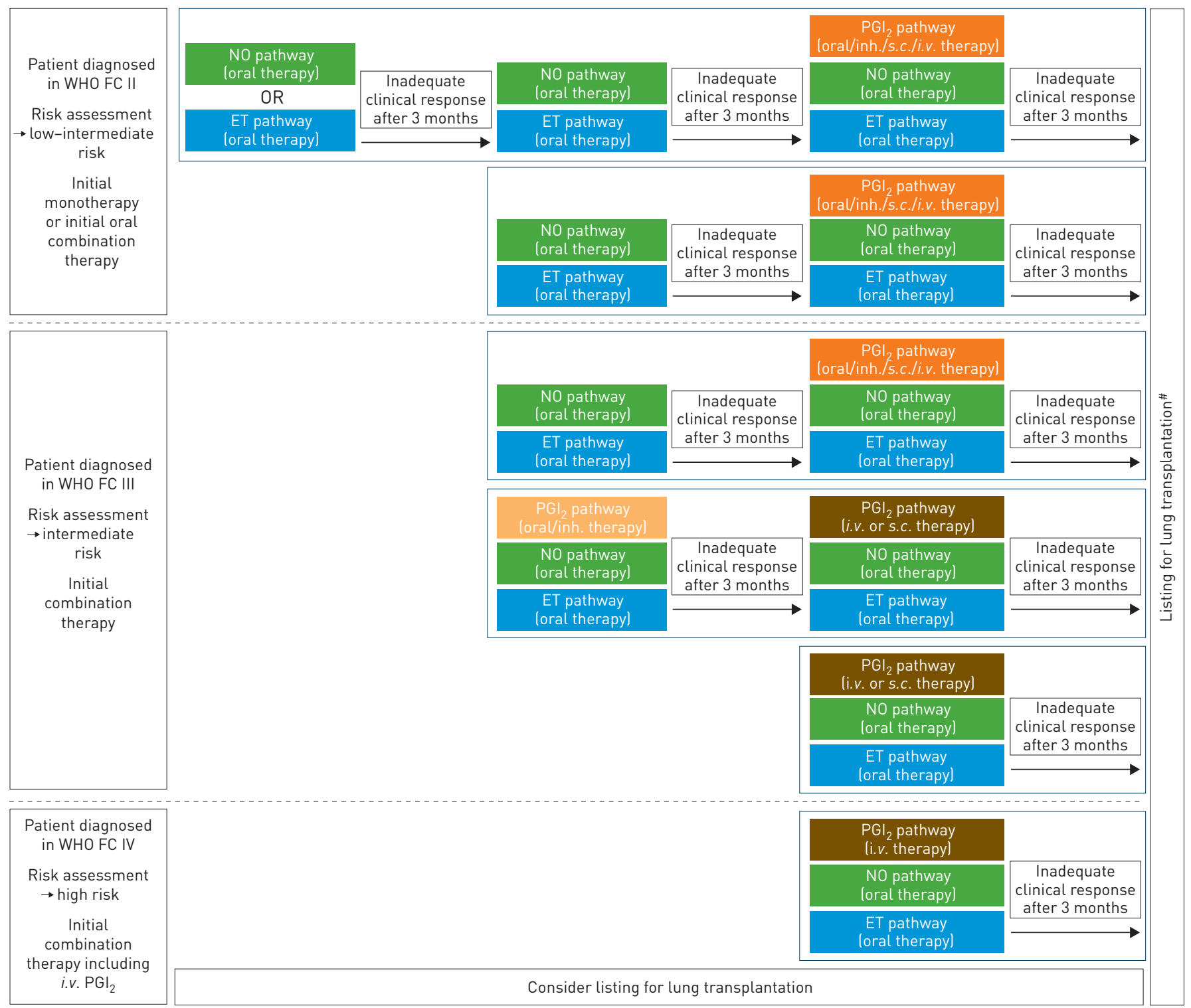

FIGURE 4 Future perspectives on the use of combination therapy to treat pulmonary arterial hypertension. The choice of combination therapy regimen will be influenced by the risk status at diagnosis and the response to initial medical therapy. Inadequate clinical response is defined as a patient who does not achieve or maintain a low-risk profile [11, 12]. WHO FC: World Health Organization functional class; N0: nitric oxide; ET: endothelin; $\mathrm{PGI}_{2}$ : prostacyclin; inh.: inhaled. ${ }^{\#}$ : for eligible patients. 


\section{Conclusions and future perspectives}

The studies presented here highlight the growing evidence for combination therapy in the successful management of $\mathrm{PAH}$, and the benefits for patients are now clear to see. Long-term outcome trials have illustrated that keeping patients on monotherapy is no longer acceptable, as adding a second and then a third drug has the potential to significantly delay disease progression [8, 10]. Based on this body of evidence, PAH patients should be offered the benefits of combination therapy whenever possible, irrespective of which treatment strategy is utilised. A suggested approach to combination therapy in $\mathrm{PAH}$, based on available evidence and our experience, is illustrated in figure 4.

Long-term studies performed to date have demonstrated that patients can benefit from both initial and sequential combination therapy [8-10]. However, the comparable efficacy of the two treatment strategies has not been formally studied. The ESC/ERS guidelines state that either sequential or initial oral combination therapy can be used to treat patients who are considered at low or intermediate risk of clinical worsening or death $[11,12]$. If a sequential combination strategy is adopted, patients must be assessed after 3-6 months of therapy initiation and subsequently every 3-6 months, and therapy must be rapidly escalated for those who fail to achieve the pre-determined treatment goals (i.e. most of the assessed parameters should be in the low-risk category) $[11,12]$. If an initial combination strategy is selected, then it is important to evaluate the safety profiles of the drugs to minimise the possibility of intolerable side-effects. Furthermore, an up-titration protocol that takes into account the requirements for all drugs will need to be determined.

The importance of targeting three distinct pathological pathways in $\mathrm{PAH}$ is becoming increasingly clear $[10,46]$ and may improve outcomes for patients who fail to achieve their treatment goals on dual combination therapy. The development of oral therapies targeting the $\mathrm{PGI}_{2}$ pathway allows triple combination therapy to be implemented earlier, in patients in WHO functional class II or III, without the burden associated with parenteral prostanoid therapies. Triple combination therapy with i.v. epoprostenol is still an important option for patients with severe PAH, and as detailed in the ESC/ERS guidelines, high-risk patients should receive initial combination therapy with i.v. epoprostenol without delay $[11,12]$.

Much progress has been made in our understanding of the role and benefits of combination therapy in the field of PAH. In the coming years, additional data are expected to fill the gaps in our knowledge, ensuring that combination therapy can be used to its full potential, providing patients with the best possible outcomes.

\section{Acknowledgements}

The authors would like to thank Anna Chapman (nspm Ltd, Meggen, Switzerland) for medical writing assistance, funded by Actelion Pharmaceuticals Ltd (Allschwil, Switzerland).

\section{References}

1 Cihlar T, Fordyce M. Current status and prospects of HIV treatment. Curr Opin Virol 2016; 18: 50-56.

2 Panel on Antiretroviral Guidelines for Adults and Adolescents. Guidelines for the Use of Antiretroviral Agents in HIV-1-infected Adults and Adolescents. Department of Health and Human Services. http://aidsinfo.nih.gov/ contentfiles/lvguidelines/AdultandAdolescentGL.pdf Date last accessed: July 2016. Date last updated: July 14, 2016.

3 Vaduganathan M, Mentz RJ, Greene SJ, et al. Combination decongestion therapy in hospitalized heart failure: loop diuretics, mineralocorticoid receptor antagonists and vasopressin antagonists. Expert Rev Cardiovasc Ther 2015; 13: 799-809.

4 Cole GD, Patel SJ, Zaman N, et al. "Triple therapy" of heart failure with angiotensin-converting enzyme inhibitor, beta-blocker, and aldosterone antagonist may triple survival time: shouldn't we tell patients? JACC Heart Fail 2014; 2: 545-548.

5 Wright JT Jr, Williamson JD, Whelton PK, et al. A randomized trial of intensive versus standard blood-pressure control. N Engl J Med 2015; 373: 2103-2116.

6 Miles D, von Minckwitz G, Seidman AD. Combination versus sequential single-agent therapy in metastatic breast cancer. Oncologist 2002; 7: Suppl. 6, 13-19.

7 Frei E, Eder JP. Principles of dose, schedule and combination chemotherapy. In: Kufe DW, Pollock RE, Weichselbaum RR, et al., eds. Holland-Frei Cancer Medicine. 8th Edn. Hamilton, BC Decker, 2003, pp. 558-568.

8 Pulido T, Adzerikho I, Channick R, et al. Macitentan and morbidity and mortality in pulmonary arterial hypertension. N Engl J Med 2013; 369: 809-818.

9 Galiè N, Barberà JA, Frost AE, et al. Initial use of ambrisentan plus tadalafil in pulmonary arterial hypertension. N Engl J Med 2015; 373: 834-844.

10 Sitbon O, Channick R, Chin KM, et al. Selexipag for the treatment of pulmonary arterial hypertension. $N$ Engl J Med 2015; 373: 2522-2533.

11 Galiè N, Humbert M, Vachiery JL, et al. 2015 ESC/ERS guidelines for the diagnosis and treatment of pulmonary hypertension. Eur Heart J 2016; 37: 67-119.

12 Galiè N, Humbert M, Vachiery JL, et al. 2015 ESC/ERS guidelines for the diagnosis and treatment of pulmonary hypertension. Eur Respir J 2015; 46: 903-975.

13 Johnson SR, Brode SK, Mielniczuk LM, et al. Dual therapy in IPAH and SSc-PAH. A qualitative systematic review. Respir Med 2012; 106: 730-739.

14 Hoeper MM, Leuchte H, Halank M, et al. Combining inhaled iloprost with bosentan in patients with idiopathic pulmonary arterial hypertension. Eur Respir J 2006; 28: 691-694. 
15 McLaughlin VV, Oudiz RJ, Frost A, et al. Randomized study of adding inhaled iloprost to existing bosentan in pulmonary arterial hypertension. Am J Respir Crit Care Med 2006; 174: 1257-1263.

16 Galiè N, Rubin L, Hoeper M, et al. Treatment of patients with mildly symptomatic pulmonary arterial hypertension with bosentan (EARLY study): a double-blind, randomised controlled trial. Lancet 2008; 371: 2093-2100.

17 McLaughlin VV, Benza RL, Rubin LJ, et al. Addition of inhaled treprostinil to oral therapy for pulmonary arterial hypertension: a randomized controlled clinical trial. J Am Coll Cardiol 2010; 55: 1915-1922.

18 Simonneau G, Rubin LJ, Galiè N, et al. Addition of sildenafil to long-term intravenous epoprostenol therapy in patients with pulmonary arterial hypertension: a randomized trial. Ann Intern Med 2008; 149: 521-530.

19 Galiè N, Brundage BH, Ghofrani HA, et al. Tadalafil therapy for pulmonary arterial hypertension. Circulation 2009; 119: 2894-2903.

20 Ghofrani HA, Galiè N, Grimminger F, et al. Riociguat for the treatment of pulmonary arterial hypertension. N Engl J Med 2013; 369: 330-340.

21 Zhuang Y, Jiang B, Gao H, et al. Randomized study of adding tadalafil to existing ambrisentan in pulmonary arterial hypertension. Hypertens Res 2014; 37: 507-512.

22 Humbert M, Barst RJ, Robbins IM, et al. Combination of bosentan with epoprostenol in pulmonary arterial hypertension: BREATHE-2. Eur Respir J 2004; 24: 353-359.

23 Tapson VF, Torres F, Kermeen F, et al. Oral treprostinil for the treatment of pulmonary arterial hypertension in patients on background endothelin receptor antagonist and/or phosphodiesterase type 5 inhibitor therapy (the FREEDOM-C study): a randomized controlled trial. Chest 2012; 142: 1383-1390.

24 Tapson VF, Jing ZC, Xu KF, et al. Oral treprostinil for the treatment of pulmonary arterial hypertension in patients receiving background endothelin receptor antagonist and phosphodiesterase type 5 inhibitor therapy (the FREEDOM-C2 study): a randomized controlled trial. Chest 2013; 144: 952-958.

25 McLaughlin VV, Channick R, Ghofrani HA, et al. Bosentan added to sildenafil therapy in patients with pulmonary arterial hypertension. Eur Respir J 2015; 46: 405-413.

26 Peacock AJ, Naeije R, Galiè N, et al. End-points and clinical trial design in pulmonary arterial hypertension: have we made progress? Eur Respir J 2009; 34: 231-242.

27 Savarese G, Paolillo S, Costanzo P, et al. Do changes of 6-minute walk distance predict clinical events in patients with pulmonary arterial hypertension? A meta-analysis of 22 randomized trials. J Am Coll Cardiol 2012; 60: 1192-1201.

28 Gabler NB, French B, Strom BL, et al. Validation of 6-minute walk distance as a surrogate end point in pulmonary arterial hypertension trials. Circulation 2012; 126: 349-356.

29 Sitbon O, Channick R, Delcroix M, et al. Effect of macitentan on haemodynamics in SERAPHIN, a randomised controlled trial in pulmonary arterial hypertension. Eur Respir J 2013; 42: Suppl. 57, P4060.

30 Channick RN, Delcroix M, Ghofrani HA, et al. Effect of macitentan on hospitalizations: results from the SERAPHIN trial. JACC Heart Fail 2015; 3: 1-8.

31 Simonneau G, Channick R, Delcroix $\mathrm{M}$, et al. Incident and prevalent cohorts with pulmonary arterial hypertension: insight from SERAPHIN. Eur Respir J 2015; 46: 1711-1720.

32 Kim NH, Chin KM, Rouzic EM, et al. OPsumit USers Registry (OPUS): insights into the safety and tolerability of Opsumit. Am J Crit Care Med 2016; 193: A7396.

33 Kim NH, Chin KM, Rouzic EM, et al. OPsumit USers Registry (OPUS): Insights into the Safety and Tolerability of Opsumit. Poster presented at American Thoracic Society Congress 2016: P1031.

34 Dardi F, Manes A, Palazzini M, et al. Combining bosentan and sildenafil in pulmonary arterial hypertension patients failing monotherapy: real-world insights. Eur Respir J 2015; 46: 414-421.

35 Lang IM, Gaine SP. Recent advances in targeting the prostacyclin pathway in pulmonary arterial hypertension. Eur Respir Rev 2015; 24: 630-641.

36 Scott LJ. Selexipag: first global approval. Drugs 2016; 76: 413-418.

37 Lang I, Gaine S, Galiè N, et al. Effect of selexipag on long-term outcomes in patients with pulmonary arterial hypertension (PAH) receiving one, two or no PAH therapies at baseline: Results from the GRIPHON study. Poster presented at European Society of Cardiology 2015: P2365.

38 Lang I, Gaine S, Galiè N, et al. Effect of selexipag on long-term outcomes in patients with pulmonary arterial hypertension $(\mathrm{PAH})$ receiving one, two or no PAH therapies at baseline: results from the GRIPHON study. Eur Heart J 2015; 36: Suppl. 1, 381-382.

39 Kemp K, Savale L, O'Callaghan DS, et al. Usefulness of first-line combination therapy with epoprostenol and bosentan in pulmonary arterial hypertension: an observational study. J Heart Lung Transplant 2012; 31: 150-158.

40 Eli Lilly. Adcirca (tadalafil). Summary of product characteristics. www.medicines.org.uk/emc/medicine/23886 Date last updated: January 15, 2016.

41 GlaxoSmithKline UK. Volibris (ambrisentan). Summary of product characteristics. www.medicines.org.uk/emc/ medicine/20848 Date last updated: November 2015.

42 Bachetti C, Manes A, Dardi F, et al. Comparison between initial combination therapy and initial monotherapy in pulmonary arterial hypertension: a single centre blinded evaluation of patients enrolled in the ambition study. Am J Respir Crit Care Med 2015; 191: A4779.

43 Hassoun PM, Zamanian RT, Damico R, et al. Ambrisentan and tadalafil up-front combination therapy in scleroderma-associated pulmonary arterial hypertension. Am J Respir Crit Care Med 2015; 192: 1102-1110.

44 Sitbon O, Sattler C, Bertoletti L, et al. Initial dual oral combination therapy in pulmonary arterial hypertension. Eur Respir J 2016; 47: 1727-1736.

45 Chin KM, Ruggiero R, Bartolome S, et al. Long-term therapy with oral treprostinil in pulmonary arterial hypertension failed to lead to improvement in important physiologic measures: results from a single center. Pulm Circ 2015; 5: 513-520.

46 Sitbon O, Jaïs X, Savale L, et al. Upfront triple combination therapy in pulmonary arterial hypertension: a pilot study. Eur Respir J 2014; 43: 1691-1697.

47 Barst RJ, Rubin LJ, Long WA, et al. A comparison of continuous intravenous epoprostenol (prostacyclin) with conventional therapy for primary pulmonary hypertension. N Engl J Med 1996; 334: 296-301.

48 The efficacy and safety of initial triple versus initial dual oral combination therapy in patients with newly diagnosed pulmonary arterial hypertension (TRITON). NCT02558231. https://clinicaltrials.gov/ct2/show/NCT02558231?term= NCT02558231\&rank=1 Date last accessed: July 2016. Date last updated: September 15, 2016. 